\title{
Fetal Biophysical Profile
}

National Cancer Institute

\section{Source}

National Cancer Institute. Fetal Biophysical Profile. NCI Thesaurus. Code C92925.

A test of fetal well-being performed using a combination of ultrasound parameters (fetal movement, fetal tone, fetal breathing, amniotic fluid) and a non-stress test (NST). 